https://cssr.uitm.edu.my/2018/

5th International Conference on Science and Social Research

Le Meridien Kota Kinabalu Hotel, 5 - 6 December 2018

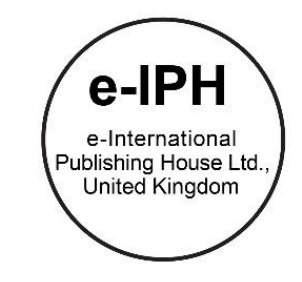

\title{
The Invention of Geospatial Decision Support System for Malaysian Tuberculosis Surveillance Data Management
}

\author{
Abdul Rauf Abdul Rasam¹, Noresah Mohd Shariff2, JilorisF Dony ${ }^{3}$ \\ ${ }^{1}$ Faculty of Architecture Planning and Surveying, \\ Universiti Teknologi MARA (UiTM), 40450 Shah Alam, Selangor, Malaysia \\ 2 Universiti Sains Malaysia, 11800 Gelugor, Penang, Malaysia \\ ${ }^{3}$ Sabah State Health Department, Ministry of Health Malaysia, 88590 Kota Kinabalu, Malaysia \\ rauf@salam.uitm.edu.my, noreshah@usm.my, jiloris.moh@1govuc.gov.my \\ Tel: +6013-5444289
}

\begin{abstract}
The World Health Organization (WHO) recognizes the capabilities of a health information tool for disease preparedness and emergency responses. In Malaysia, the Ministry of Health (MOH) has been using MyTB system to support the national tuberculosis (TB) control program through data decision-making management. However, this present system does not seem to be considering geospatial element which is one of the important factors affecting TB control. Integrating the MyTB system with geospatial functions would enhance the explicit cognitive and behavior analyses of TB by proposing a MyGeoTBIS ${ }^{\circ}$ to assist the local health authorities in exploring TB dynamics and multi-level infection control.
\end{abstract}

Keywords: Geospatial, GIS, MyGeoTBIS, MyTB, tuberculosis disease

eISSN: 2398-4287@ 2020. The Authors. Published for AMER ABRA cE-Bsby e-International Publishing House, Ltd., UK. This is an open access article under the CC BYNC-ND license (http://creativecommons.org/licenses/by-nc-nd/4.0). Peer-review under responsibility of AMER (Association of Malaysian Environment-Behaviour Researchers), ABRA (Association of Behavioural Researchers on Asians) and cE-Bs (Centre for Environment-Behaviour Studies), Faculty of Architecture, Planning \& Surveying, Universiti Teknologi MARA, Malaysia.

DOI: https://doi.org/10.21834/ebpj.v5iSI3.2564

\subsection{Introduction}

TB situation in Malaysia is a medium level and still a public concern, thus the implementation of a local computerized information system of TB namely MyTB can assist to a certain extent in case management and contact investigation. This non-spatial web-based system has its functions and modules, including the menu of general info, surveillance, treatment centres, contact, download, reports, and maintenance. The system keeps the notification case and acts as disease control and prevention plan in the country.

Although the current system of MyTB has strength in terms of data collection, processing, and distribution, the lack of geospatial assimilation in the system needs to be further enhanced for a better TB information system and decision-making process. A geospatial or geographic data element is physical information that can be represented in a geographic coordinate system and attribute datasets. A GIS can produce maps of the exposure and disease to reveal spatial patterns and predict the complex phenomena. Previous studies have practically proven that the technology can be used in TB epidemiological management, disease mapping, risk assessment and spread prediction (Abdul Rasam et al., 2016; Carroll et al., 2014; Li et al., 2014; Pfeiffer \& Stevens, 2010; Zhao et al., 2013, Rasam et al., 2017).

eISSN: 2398-4287C 2020. The Authors. Published for AMER ABRA cE-Bsby e-International Publishing House, Ltd., UK. This is an open access article under the CC BYNC-ND license (http://creativecommons.org/licenses/by-nc-nd/4.0/). Peer-review under responsibility of AMER (Association of Malaysian Environment-Behaviour Researchers), ABRA (Association of Behavioural Researchers on Asians) and cE-Bs (Centre for Environment-Behaviour Studies), Faculty of Architecture, Planning \& Surveying, Universiti Teknologi MARA, Malaysia. DOI: https://doi.org/10.21834/ebpj.v5iSI3.2564 
The motivation of this research is raised when related theories and scholarly experts convince that the GIS function has abilities to be applied in epidemiology and health studies as conducted in local studies (Rasam et al., 2018; Bazlan et al., 2014; Mohd Noor et al., 2011). Clarke et al. (1996) and Abdul Rasam et al. (2019) highlighted the GIS provides new and intensifying opportunities for epidemiology and believed that the technology prospect has already maintained a role for the public health expert in geography. Jarup (2004) added that these roles utilize disease mapping to reveal spatial patterns, exposure assessment in ecological epidemiology, and risk estimation to explore disease changes and environmental patterns. In Malaysia, Abdul Rasam et al., (2016) indicated a GISMCDM approach can identify the potential risk areas of TB using selected environmental risk factors. By bringing the geospatial values in the context of the local MyTB system, this will optimize its current analytical competencies and transform the national health delivery system into a global inspiration as established in this exploratory research of MyGeoTB॰ (Abdul Rasam et al., 2017a).

\subsection{Material and Method}

This study was carried out by using the method of the case study. By using a study area as a case, the study was carried out to cover System design and framework: System design is a preliminary idea about the innovative system and how it will function to meet the user requirement (Stair \& Reynolds, 2008), including conceptual design, logical design, and physical design. Conceptually, the idea, entity, and relationship between entities were adapted from the TB transmission in which related to the epidemical elements of people (cases), place (location), and temporal (time). These elements could be translated into practical implementation through a geospatial health approach.

Therefore, the analytical framework of GIS operations (Chang, 2011) and spatial epidemiological methodology (Pfeiffer et al, 2008) are innovatively combined to be applied in the MyTB database system and developed a dynamic MyGeoTBIS framework and prototype. This combined framework may also be suitable for related infectious disease applications towards a powerful tool to assist TB policy development and disease prevention and control. Figure 1 displays several main steps used in the research, starting from geodatabase development to geoinformation dissemination. Data and instruments used in the study are also quite common in Malaysia such as the disease cases, GIS-environmental data, and spatial-statistical packages.

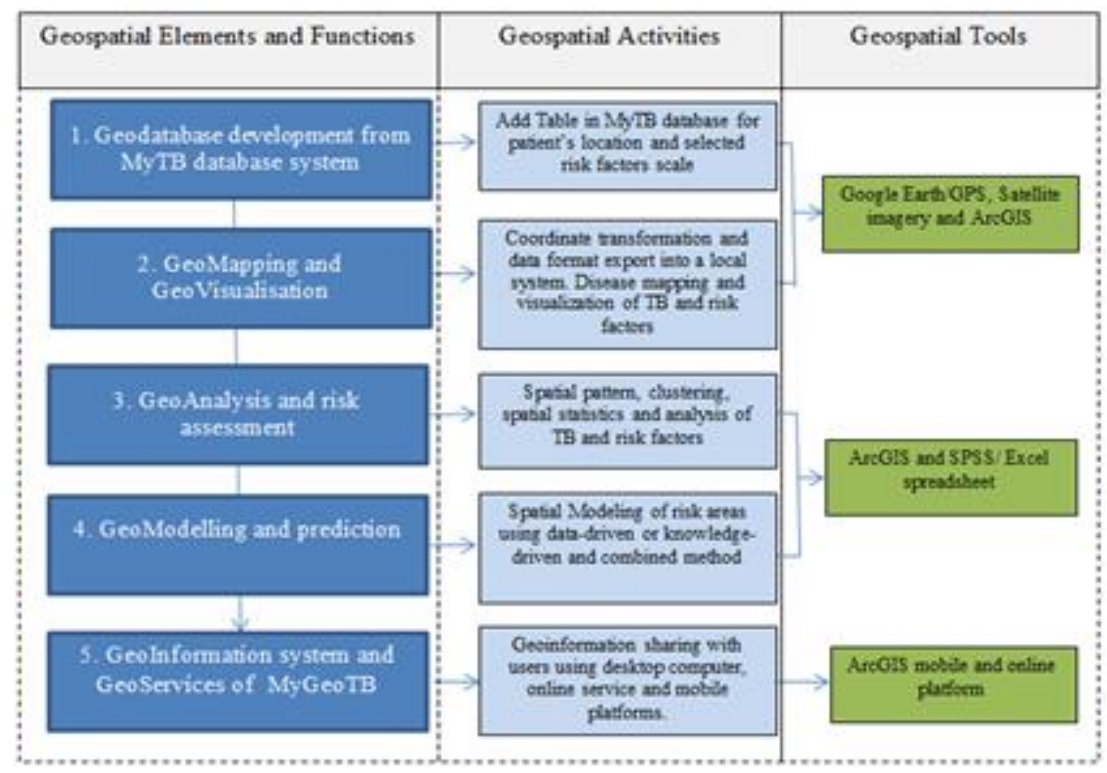

Fig 1: A MyGeoTBIS framework and prototype (Abdul Rasam et al,

The system development of MyGeoTBIS was built according to MyGeoHealth system framework designed as presented in Fig. 1. It involves five phases: Geodatabase creation, GeoMapping, and GeoVisualization, GeoAnalysis, GeoModelling, and Geoinformation Dissemination. Two approaches were applied to collect the data, which are primary and secondary data collection. Primary research consists of a collection of original primary data collected by the researcher especially from expert opinions (health officers from PKD, Petaling) and site visits at the high-risk areas. While secondary data refers to data that were collected by others such as TB cases from MyTB System and spatial data related to risk factors. ArcGIS Desktop and ArcGIS Online are two main platforms used to design and develop the system.

GeoDatabase Development: The main function in this step is to input the spatial data element into the existing MyTB database by adding the field of location's table and then inserting the coordinate values. Collecting GPS coordinates and ground knowledge at the real site is required to verify the ambiguous addresses. Other fields are specifically for the weighed scale of selected risk factors that are derived from a holistic MyTBRisk Index ${ }^{\odot}$, an inventive Malaysian integrated risk factor index according to global indicators. The index covers the level of urbanization, the density of population, closeness to the industrial area, types of housing, the distance of 
TB-healthcare facilities, the status of household income, level of a high-risk group, and level of human mobility or movement concentration. The five-score scale is calculated from the combination values from the expert's opinion, existing theories, and previous studies. The scale of 1 to 5 shows the lowest and the highest level of risk area, respectively as studied by Abdul Rasam et al., (2016).

GeoMapping and GeoVisualization: The core function in this graphical step consists of disease mapping and visualization. The distribution of disease localities can be displayed either using GPS coordinates or Google Earth/Map-based coordinates (kml file). Data or file from Google Earth/Map needs to be transformed and exported into a local system, which is Rectified Skew Orthomorphic Geocentric Datum Malaysia 2000 (RSO_GDM2000) and shapefile before mapping them in ArcGIS platform (ArCatalog and ArcMap). The mapping is visualized in a point and a continuous pattern or in a two-dimensional or a three-dimensional view. Data manipulation or imagery superimposition is also conducted for enhanced interpretation of the disease before conducting further in-depth analysis.

GeoAnalysis and GeoModelling: This analytical involves a geospatial data analysis which comprises of a basic and advanced analytical technique. Descriptive data analysis is a common technique in ArcGIS and SPSS platform involving the activities of general trends exploration, data subset overview, and correlational examination among datasets. For example, the attribute or locality selection tool can be used to select the closest factory from the housing areas, and then create the buffer zone (e.g. less than 250 meters) for risk data classification, aggregation, and map comparison. For advanced tools, geostatistical and regression techniques can be manipulated in Arctoolbox for exhaustive TB risk assessment and management. GeoModelling or GIS modelling is an advanced analytical function that refers to meticulous work to get an improved predictive result of potential risk areas of TB.

Geolnformation Dissemination: This flexible distribution function covers a geoinformation system and sharing for decision making and awareness purposes. A web mapping in GIS can fascinate a lot of users to create crowdsourcing information for national TB response, health relief, and promotion. A collaborative web mapping services such as Google Earth, Google Map, Microsoft Virtual Earth, and Google My Maps can become a 'TB promoter' to increase the knowledge and consciousness about TB and its prevention among the public especially in marginal and rural areas. Nonetheless, TB data are regarded as highly confidential in certain countries and these data are protected whereby one needs to obtain permission from the respective local authority for public publication.

\subsection{Results and Discussion}

\section{The uniqueness of the System Elements and Frameworks}

MyGeoTBIS is a geospatial decision support system that was initially proposed in Shah Alam Malaysia. A Geospatial data has spatial characteristics that can be used to understand the basic elements of TB etiology, while geospatial operations are employed to collect, manage and disseminate the data using a geographical information system (GIS), a global positioning system (GPS), satellite imagery, and web mapping services. The system has demonstrated the geospatial capabilities in enhancing the current system functions towards practicable applications. A geoSpatial framework of GIS operations and spatial epidemiological methodology are innovatively integrated to be applied in the MyTB database system and developed a dynamic MyGeoTBIS prototype as shown in Fig. 2. By implementing these geospatial elements and framework, the local health staff who are not familiar with geospatial technology can easily use this methodology compared to the existing ways to manage, analyse and display the result of airborne disease data and information.

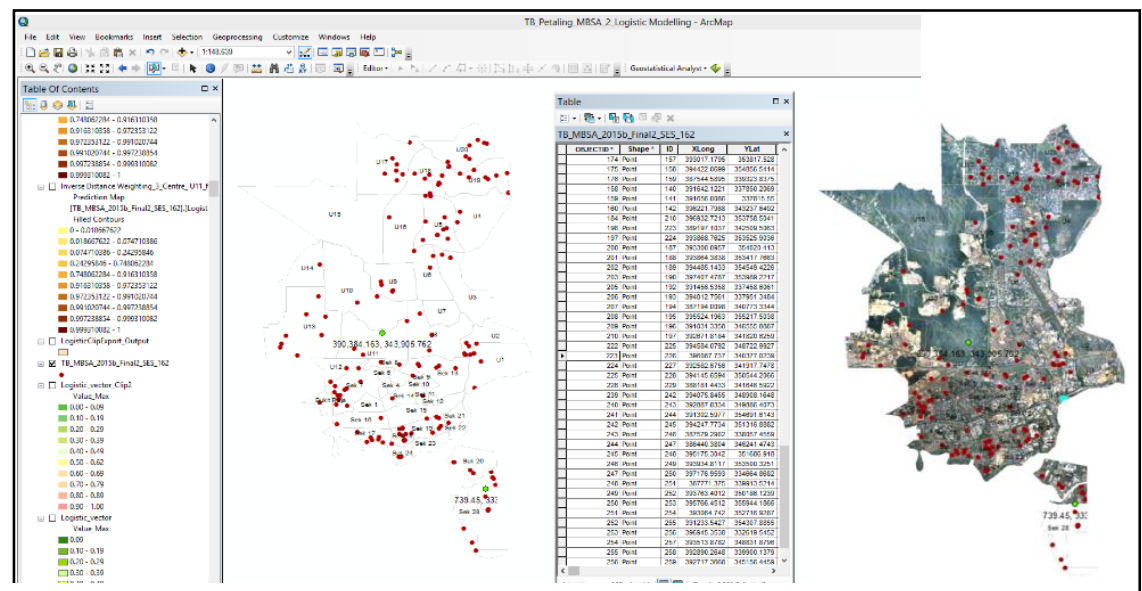

Fig 2: The main interface of the MyGeoTBIS, showing a Geodatabase and GeoMapping of TB

Practical Functions of the System Methodology

MyGeoTBIS has demonstrated how the functional contents of the existing system of MyTBIS can be improved by absorbing geospatial elements and GIS operations towards developing a more dynamic analysis and predictive pattern of local TB. The main uniqueness of the MyGeoTBIS is the methodological framework is appropriate with a study of any infectious diseases, especially for human airborne epidemics. It comprises TB GeoDatabase Development, TB GeoMapping, and GeoVisualization, TB GeoAnalysis and GeoModelling, 
and TB Geolnformation System and GeoServices (Abdul Rasam et al, 2017). For example, as exposed in Fig. 3, the locations of TB and their relationship with potential risk factors (such as factory location) could be predicted by determining their shortest distance with the residential areas. For this prediction, quantitative association or prediction of TB risk locations could be then estimated by using advanced geoanalysis and geomodelling.

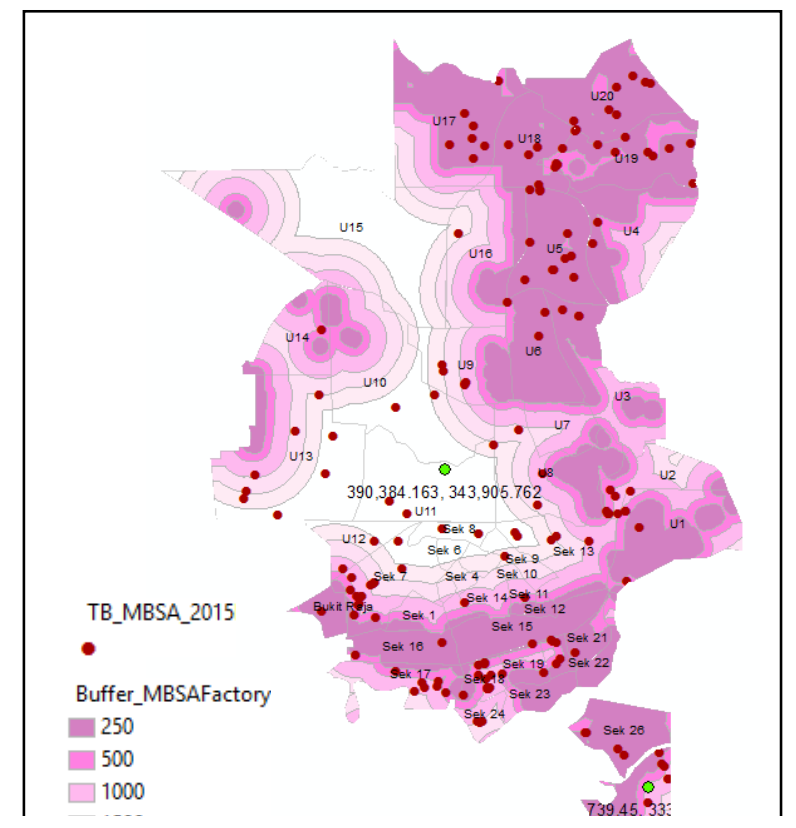

Fig 3: GeoAnalysis (buffering) of possible risk relationship between industrial factory and residential areas towards a local TB GeoModelling

\section{Actual Applications in Monitoring Airbe}

Health organizations and the public can use the MyGeoTBIS prototype for assisting them to identify the potential TB endemic areas and targeted surveillance intervention program as conducted at Section 27, Shah Alam (Fig. 4). This prototype could then predict TB incidence for case detection and TB screening at the sites If this product is successfully developed and implemented, the burdens of healthcare works, and costs would be reduced accordingly, especially to other high-burden TB regions in the world.

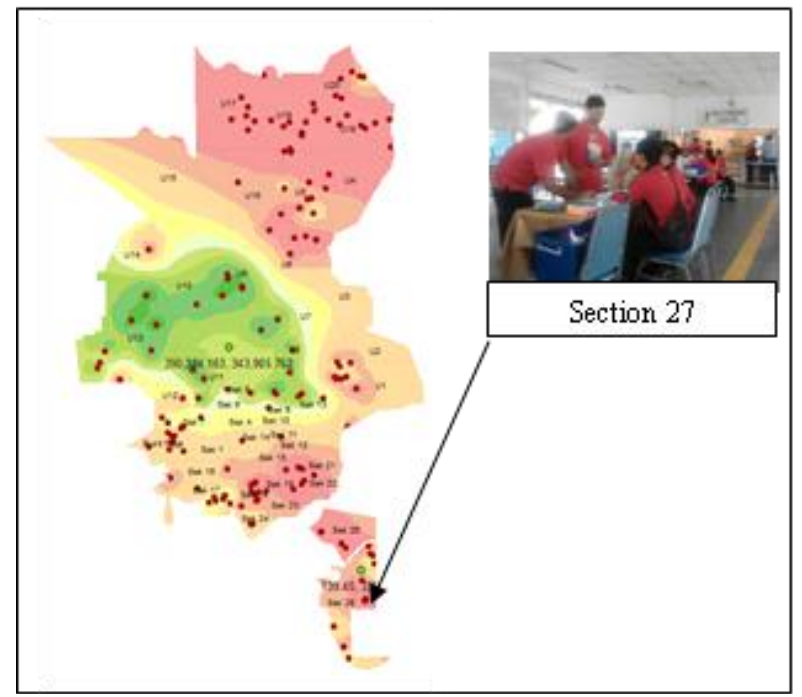

Fig 4: TB screening programme at the site using a TB risk Geomodelling in MyGeoTBIS and residential areas

Public and health officers can also use the MyGeoTBIS prototype to indicate TB disease distribution and sharing them online with others for better public health awareness and promotion platform. For example, the public can identify the hotspots and the possible closest healthcare centres for TB screening and prevention purposes by applying ArcGIS Online web map as displayed in Fig. 5. 
Overall, the proposed framework could enhance the existing technical functions of the system for a better national TB management information and decision support system.

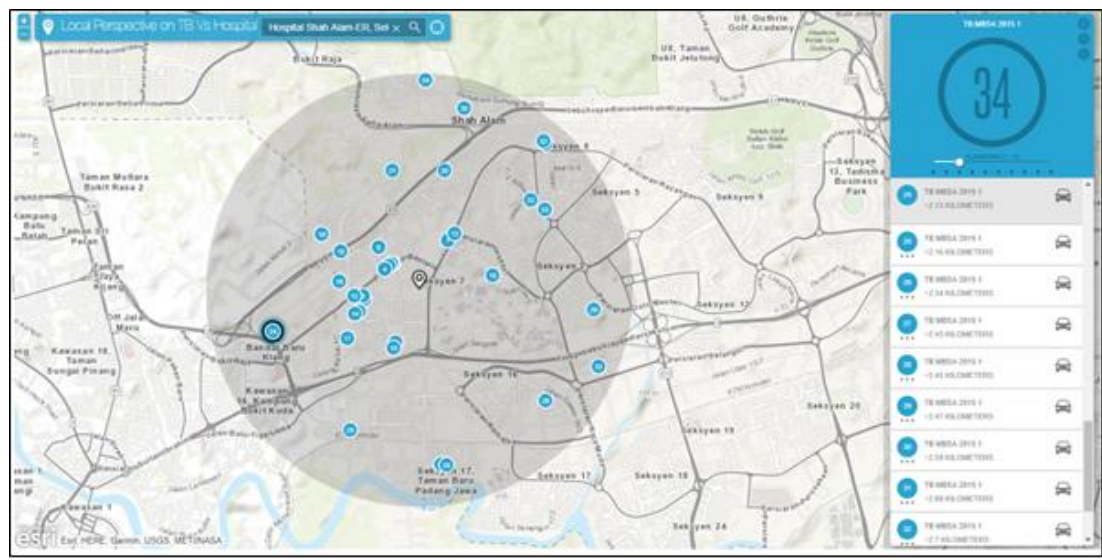

Fig 5: Geoinformation services between health officers and the public for public health awareness and promotion of TB cases in Shah Alam.

\section{Current and Future Directions}

This research presents the ability of geospatial and GIS technology as an analytical framework to improve the existing Malaysian TB information systems towards a better predictive analysis and support system. Earlier studies have shown the capabilities of geospatial functions for TB data mapping, analysis, modelling and management (Carroll et al., 2014; Li et al., 2014; Pfeiffer \& Stevens, 2010; Zhao et al., 2013). However, since this study is in its prototype stage, there are several considerations to be taken into account before using it in a practicable way. The proposed steps in the framework can be applied by users with relevant modifications according to local situations and provide a reasonable result. For example, certain health organizations might not be doing geoinformation services to the public because of the confidentiality issues i.e. the data are not allowed to be published on the Internet.

\subsection{Conclusion}

Complexities of the current pattern of local TB occurrences require a flexible capacity technology to support disease management information systems, reducing staff workloads and technical cost. Thus, the establishment of the MyTB application in Malaysia proves that information systems can assist in controlling TB in line with World Health Organization's objective in promoting the use of technology to reduce the number of TB cases. Since TB cases are also often associated with the spatial environment, the element of geospatial such as GeoMapping, GeoAnalysis, and GeoModelling should be indirectly included in the established MyTB for better understanding on the TB epidemiology. Geospatial technology has hands-on potentials to analyse the TB dynamics using ecological risk factors. Health officers can use the MyGeoTBIS prototype to indicate TB disease patterns and sharing with others for better public health awareness and promotion platforms. More interestingly is that the prototype can also predict TB incidence for case detection and TB screening at the sites. Nonetheless, the efforts to stabilize the prototype practicality are continuously needed to find relevant techniques that are appropriate for the prototype. In a nutshell, the proposed framework of the prototype could enhance the existing technical functions of the system for better national TB management information and decision support analysis system.

\section{Acknowledgment}

The authors would like to acknowledge the TB and Leprosy Sector of the Ministry of Health Malaysia and the Selangor States Health Department for providing TB datasets in this research paper. This research has been registered in the National Medical Research Register, Malaysia (ID: NMR R -15-2499-24207). Universiti Teknologi MARA Selangor is also thankful for providing a research fund (600-IRMI/PERDANA 5/3 BESTARI (052/2018).

\section{References}

Abdul Rasam, A. R., Shariff, N. M., \& Dony, J. F. Sulaiman S. A. (2019). Geospatial Tuberculosis Information System for Airborne Disease Management. Jurnal Inovasi Malaysia, [S.I.], v. 2, n. 1, p. 75-88. https://joms.uitm.edu.my/index.php/jurim/article/view/43. Date accessed: 20 May 2020.

Abdul Rasam, A. R., Shariff, N. M., \& Dony, J. F. (2016). Identifying high-risk populations of tuberculosis using environmental factors and GIS-based multi-criteria decision-making methods. ISPRS - International Archives of the Photogrammetry, Remote Sensing and Spatial Information Sciences, XLII-4/W1(October), 9-13. doi:10.5194/isprs-archives-XLII-4-W1-9-2016 
Abdul Rasam, A.R., Shariff, N. M., \& Dony, J. F. (2017a). MyTBRisk Index: Malaysian integrated tuberculosis risk index. Unpublished Work. Copyright by Malaysian Intelectual Property Right.Malaysia.

Abdul Rasam, A.R., Shariff, N. M., \& Dony, J. F. (2017b). MyGeoTB System: Malaysian geospatial and tuberculosis information system. Unpublished Work. Copyright by Malaysian Intelectual Property Right.Malaysia.

Bazlan MJ, Ghazali R, Abdul Rasam AR, Aziz NFA (2014) Development of integrated infectious disease information system (IDIS): geospatial-based components for malaria information system (GeoMIS) 2014 IEEE 5th control and system graduate research colloquium, Shah Alam, pp 75-79. https://doi.org/10.1109/icsgrc.2014.6908699

Chang, K. (2011). Introduction to geographic information systems., New York, USA: McGraw Hill.

Carroll, L. N., Au, A. P., Detwiler, L. T., Fu, T.-C., Painter, I. S., \& Abernethy, N. F. (2014). T-Visualization and analytics tools for infectious disease epidemiology: A systematic review. Journal of Biomedical Informatics, 51C, 287-298. doi:10.1016/j.jbi.2014.04.006

Clarke, K. C., Ph, D., Mclafferty, S. L., \& Tempalski, B. J. (1996). On epidemiology and geographic information systems : A review and discussion of future directions. Emerging Infectious Diseases, 2(2), 85-92.

Craft, M., Read, J. \& Christley, R.. (2011). Social networks and the spread of infectious diseases Disease Ecology Individual, Retrieved from http://www.nimbios.org/workshops/talks/WS_cats_rabies_Craft.pdf.

Hossain, I., Firdausy, T.P. \& Behr, F.J. (2010). WHO's Public health mapping and GIS programme in Geoinformatics, Applied Geoinform, Environment Ambiente, Medio. 87-92.

Jarup, L. (2004). Health and Environment Information Systems for Exposure and Disease Mapping, and Risk Assessment. Environmental Health Perspectives, 112(9), 995-997. doi:10.1289/ehp.6736

Li, X.-X., Wang, L.-X., Zhang, H., Jiang, S.-W., Fang, Q., Chen, J.-X., \& Zhou, X.-N. (2014). Spatial variations of pulmonary tuberculosis prevalence co-impacted by socio-economic and geographic factors in People's Republic of China, 2010. BMC Public Health, 14(1), 257. doi:10.1186/1471-2458-14-257

Manjourides, J. (2012). Identifying multidrug-resistant tuberculosis transmission hotspots using routinely collected data. Tuberculosis (Edinburgh, Scotland), 92(3), 2739. Retrieved from ttp://www.pubmedcentral.nih.gov/articlerender.fcgi?artid=3323731\&tool=pmcentrez\&rendertype=abstract

Mohd Noor AM, Abdul Rasam AR, Ahmad N (2011) Ghazali R MyGeoHealth: GIS-based cholera transmission risk system in Sabah, Malaysia. In: IEEE 7th international colloquium on signal processing and its applications, Penang, pp 474-479. https://doi.org/10.1109/cspa.2011.5759925

Narasimhan, P. (2013). Risk factors for tuberculosis. Pulmonary medicine, 2013, 1-11. Retrieved from http://www.pubmedcentral. nih.gov/articlerender.fcgi?artid=3583136\&tool=pmcentrez\&rendertype=abstract.

O'Brien, D.J. (2011). Recent advances in the management of bovine tuberculosis in free-ranging wildlife. Veterinary microbiology, 151(1-2), 23-33. Retrieved from http://www.ncbi.nlm.nih.gov/pubmed/21420260

Pfeiffer, D. U., \& Stevens, K. (2010). Using Data and Knowledge driven Approaches for Spatial Modelling. 1-44.

Pfeiffer, D., Robinson, T., Stevenson, M., Stevens, K., Rogers, D., \& Clements, A. (2008). Spatial analysis in epidemiology. New York, USA: Oxford University Press

Rasam A.R.A.; Mohd Shariff N.; Dony J.F.; Maheswaran, P.: Mapping Risk Areas of Tuberculosis Using Knowledge-Driven GIS Model in Shah Alam, Malaysia Pertanika Journal of Social Sciences \& Humanities, 2, pp. 135-144 (2017).

Rasam, A.R., Shariff, N.M., Dony, J.F., \& Misni, A. (2018). Socio-Environmental Factors and Tuberculosis: an Exploratory Spatial Analysis in Peninsular Malaysia. International journal of engineering and technology, 7, 187-192.

Stair, R. M., \& Reynolds, G. W. (2008). Fundamentals of Information Systems (4th ed.). Thomson Course Technology.

Studnicki, J., Berndt, D.J. \& Fisher, J.W. (n.d) Using information systems for public health administration. In Jonas and Bartlett, 353-380. Retrieved from https://pdfs.semanticscholar.org/f7ca/06a9671525048ebe499943509758c0e8aa43.pdf.

Zhao, F., Cheng, S., He, G., Huang, F., Zhang, H., Xu, B., ... Wang, L. (2013). Space-time clustering characteristics of tuberculosis in China, 2005-2011. PloS One, 8(12), e83605. doi:10.1371/journal.pone.0083605 